\title{
Sinonasal Inverted Papilloma and the Dilemma of Treatments
}

Bandar M Al-Qahtani, Mariam S Al-Amro

\begin{abstract}
This is a review of most recent literature to find the best methods for management of sinonasal inverted papilloma and if there is any standardized modality/modalities. Also there is concern about the advancement in the management of sinonasal inverted papilloma based on recent literature revision. Inverted papilloma has to be managed aggressively from the beginning putting in mind its ability to recur and malignant transformation. Until now days there is no single verified modality of treatment and the choice of the best approach is tailored to every case.
\end{abstract}

Keywords: Sinonasal, Inverted papilloma, Management, Review.

How to cite this article: Al-Qahtani BM, Al-Amro MS. Sinonasal Inverted Papilloma and the Dilemma of Treatments. Clin Rhinol An Int J 2013;6(2):61-63.

Source of support: Nil

Conflict of interest: None declared

\section{INTRODUCTION}

Sinonasal papilloma is a benign neoplasm arising from the mucosal lining of the sinonasal cavity. It accounts for 0.5 to $4 \%$ of all primary nasal tumors. ${ }^{1}$ It exhibits a strong male predominance and usually occurs between 50 and 69 years. The World Health Organization subdivides sinonasal papilloma into three histological types: inverted papilloma, cylindrical (columnar) papilloma and exophytic papilloma (fungiform). ${ }^{2}$ Of the three different sinonasal papilloma subtypes, inverted papilloma has been the focus of much attention and controversy. This is related primarily to the poorly understood pathogenesis and aggressive clinical behavior of this lesion. ${ }^{3}$

Inverted papilloma or Schneiderian papilloma inverted type is the most frequent variant, representing almost $70 \%$ of all sinonasal papillomas. ${ }^{4}$ Inverted papillomas were first described in 1854 by Ward and Billroth and later characterized histologically by Ringertz in $1938 . .^{5}$ The characteristic microscopic feature of inverted papilloma is digitiform proliferation of squamous epithelium into the underlying stroma. Unlike most papillomas of the body, this mucosal lesion inverts, rather than everts, into the underlying connective tissue stroma. ${ }^{6}$

The unique characteristics of inverted papilloma are its tendency to recur, its destructive expansion into the surrounding structures and its potential for malignant transformation mainly squamous cell carcinoma (SCC) which occur in about 5 to $21 \%$ of the cases.$^{5-7}$ Classically, the tumor originates from the lateral nasal wall, particularly in the osteomeatal complex area of the middle meatus, and adjacent inferior and middle turbinates, and subsequently involves the contiguous paranasal sinuses, with the maxillary sinus as the most frequent sinuss involved and ethmoid sinus as the second most common. ${ }^{1,5,7}$ Unilateral nasal obstruction and intermittent epistaxis are the most common presenting symptoms. ${ }^{5-8}$

\section{STUDY DESIGN}

A literature review of articles from 2007 to 2012 about the evolution in the management of sinonasal inverted papilloma.

\section{RESULTS AND DISCUSSION}

Treatment of inverted papilloma had gone under discussion in the last century.

The mainstay of treatment since that time is complete removal of the tumor and the method of choice depends on technology available, extent and type of the disease, site of involvement and the skill of the surgeon. ${ }^{9}$

Historically, inverted papilloma was treated with a traditional open approach, i.e. lateral rhinotomy, sublabial degloving, medial maxillectomy and craniofacial resection. ${ }^{2,5}$ Complications occurred as in any surgery and the most serious are those related to the orbit, e.g. diplopia, blepharitis or ectropion and to the central nervous system, e.g. CSF leak. Other complications such as oroantral fistula, vestibular stenosis, infection and, etc. had been reported. ${ }^{4}$

The cause behind the use of these aggressive approaches is related to the characteristics of the inverted papilloma. ${ }^{6}$ First the ability of the tumor to recur is highly variable and was reported to be 0 to $86 \%^{1,5-7,10}$ even after free period up to 7 years $^{7}$ or more in some studies. ${ }^{3}$ Second is its destructive expansion and third is the tendency for malignant transformation reaching to $21 \%$ mostly SCC. ${ }^{1,5,7}$

The introduction of endoscopes and their wide use in nasal surgery has changed the view of management of inverted papilloma and their technological advancements, including improved optics, angled endoscopes and computer-aided navigation has led many surgeons practicing them nowadays instead of the traditional open technique. . $^{5,10}$

At the beginning endoscopes were used combined with the open approach but soon endoscopic surgery was the surgery of choice as their advantages were supported by 
many studies in the literature. ${ }^{2,7,11-14}$ Endoscopic surgery has complications as the open approach but occurring in lower rates. They have no facial incision, less crusting, less bleeding, less postoperative pain, less perioperative morbidity, shorter hospital stay and less health care costs in comparison with the open approach. ${ }^{2,4-6,10,12}$ The endoscopic approach has the feature that is more physiological, facilitating preservation of normal sinonasal function. ${ }^{1,10}$ They are associated with lower recurrence rates. ${ }^{6,7,15}$ Endoscopes can be used as adjunct to open approach in selected cases. ${ }^{2,7}$

Many studies had been conducted regarding the introduction of different substances in order to decrease the recurrence rate, incidence of malignant transformation and the need for other surgery.

SK Kaluskar et al did a study about endoscopic excision with the use of $532 \mathrm{~nm}$ KTP laser. The most attracting advantage is having bloodless surgical field. None of the patients in the study complained of epistaxis, infection, excessive pain or gross nasal obstruction postoperatively. One patient experienced a recurrence after 12 months of disease-free period. He was treated with the same endoscopic laser procedure and he remained disease-free throughout the remainder of the study. The authors' believe that for inverted papilloma limited to nose and paranasal sinuses their approach is a good option in view of the low rates of recurrence and the minimal postoperative morbidity. ${ }^{6}$

Mitomycin-c is another modality of adjunct therapy that was studied. Malcolm Woodcock et al used $0.02 \%$ mitomycin C (MMC) in recurrent inverted papilloma of the lacrimal sac. Conclusion was external dacryocystorhinostomy using $\mathrm{MMC}$, as an adjuvant therapy, is a novel approach to the treatment of Schneiderian papilloma of the nasolacrimal tract. It allows preservation of function, compared with the conventional treatment of dacryocystectomy. ${ }^{16}$

Jasna But-Hazdic et al did a study to evaluate the role of radiotherapy in patients who had inverted papilloma and SCC. They concluded that combination of surgery and postoperative radiotherapy dose levels in a range used for invasive SCC are recommended for operable disease. For nonresectable disease, radical radiotherapy to a dose of 66 to $70 \mathrm{~Gy}$ could be of benefit with potential for long-lasting remission or even cure. ${ }^{8}$

Michael Rutenberg et al conducted another study about radiation therapy for sinonasal inverted papilloma and concluded that radiation therapy should be considered in patients with SCC, multiply recurrent inverted papilloma, and incompletely resectable inverted papilloma. Radiation therapy is associated with a relatively low risk of severe complications, but local failure remains a considerable challenge. ${ }^{17}$
Chemotherapeutic agents are another modality that had been tried in the management of sinonasal SCC. Ehab $Y$ Hanna et al tried induction chemotherapy with taxane and platinum by themselves or in combination with a third agent, ifosfamide or 5-fluorouracil for advanced SCC of the paranasal sinuses. The conclusion was that the tumor response to induction chemotherapy may be predictive of treatment outcome and prognosis. Favorable response to induction chemotherapy is associated with better survival and a reasonable chance of organ preservation. ${ }^{18}$

Susumu Okanu et al used another chemotherapeutic agents; docetaxel, cisplatin and S-1 followed by proton beam therapy concurrent with cisplatin in patients with $\mathrm{T} 4 \mathrm{~b}$ nasal and sinonasal malignancies. This modality was well tolerated and displays promising antitumor activity that warrants further investigation. ${ }^{19}$

\section{CONCLUSION}

From this literature review we observed that inverted papilloma management is a challenging subject which is related to its unique features. The new view of management is migrating away from the traditional open approach toward the endoscopic surgery to have less perioperative morbidity and good cure rates. Follow-up is an important issue to detect any recurrence or malignant changes as soon as possible. More studies should be conducted regarding the use of adjunct treatment to surgery for the primary disease, the recurrence and malignant changes as the reviewed articles showed responses and suggested for further investigation.

\section{REFERENCES}

1. Liu Q, Yu H, Minovi A, Wei W, Wang D, Zheng C, Li F, Zhang Z. Management of maxillary sinus inverted papilloma via transnasal endoscopic anterior and medial maxillectomy. ORL J Otorhinolaryngol Relat Spec 2010;72(5):247-251.

2. Gras-Cabrerizo JR, Montserrat-Gili JR, Massegur-Solench H, León-Vintró X, De Juan J, Fabra-Llopis JM. Management of sinonasal inverted papillomas and comparison of classification staging systems. Am J Rhinol Allergy 2010 Jan-Feb;24(1):66-69.

3. Saha SN, Ghosh A, Sen S, Chandra S, Biswas D. Inverted papilloma: a clinicopathological dilemma with special reference to recurrence and malignant transformation. Indian J Otolaryngol Head Neck Surg 2010 Oct-Dec;62(4):354-359.

4. Sadeghi N, Meyers AD. Sinonasal papillomas. Available form: http://emedicine.medscape.com/article/862677-overview.

5. Wood JW, Casiano RR. Inverted papillomas and benign nonneoplastic lesions of the nasal cavity. Am J Rhinol Allergy 2012 Mar-Apr;26(2):157-163.

6. Kaluskar SK, Mehta R, Farnan TB, Basha SI. Endoscopic 532-nm KTP laser excision of inverted papilloma of the nose and paranasal sinuses: a series of 9 patients. Ear Nose Throat $\mathrm{J}$ 2009 Apr;88(4):880-887.

7. Woodworth BA, Bhargave GA, Palmer JN, Chiu AG, Cohen NA, Lanza DC, Bolger WE, Kennedy DW. Clinical outcomes 
of endoscopic and endoscopic-assisted resection of inverted papillomas: A 15-year experience. Am J Rhinol 2007 SepOct;21(5):591-600.

8. But-Hadzic J, Jenko K, Poljak M, Kocjan BJ, Gale N, Strojan P. Sinonasal inverted papilloma associated with squamous cell carcinoma. Radiol Oncol 2011 Dec;45(4):267-272.

9. Anari S, Carrie S. Sinonasal inverted papilloma: narrative review. J Laryngol Otol 2010 Jul;124(7):705-715.

10. Yoon BN, Batra PS, Citardi MJ, Roh HJ. Frontal sinus inverted papilloma: surgical strategy based on the site of attachment. Am J Rhinol Allergy 2009 May-Jun;23(3):337-341.

11. Carta F, Verillaud B, Herman P. Role of endoscopic approach in the management of inverted papilloma. Curr Opin Otolaryngol Head Neck surg 2011 Feb;19(1):21-24.

12. Osuch-Wójcikiewicz E, Wojas O, Nyckowska J, Checiñski $P$, Sielska-Badurek E, Bruzgielewicz A, Szwedowicz P, Niemczyk $\mathrm{K}$. Management of recurrent sinonasal inverted papilloma in the experience of ENT Department Medical University of Warsaw. Otolaryngol Pol 2010 Jun;64(7):73-76.

13. Douglas D Reh, Andrew P Lane. The role of endoscopic sinus surgery in the management of sinonasal inverted papilloma. Curr Opin Otolaryngol Head Neck Surg 2009 Feb;17(1):6-10.

14. Sautter NB, Cannady SB, Citardi MJ, Roh HJ, Batra PS. Comparison of open versus endoscopic resection of inverted papilloma. Am J Rhinol 2007 May-Jun;21(3):320-323.

15. Giotakis E, Eleftheriadou A, Ferekidou E, Kandiloros D, Manolopoulos L, Yiotakis I. Clinical outcomes of sinonasal inverted papilloma surgery. A retrospective study of 67 cases. B-ENT 2010;6(2):111-116.
16. Woodcock M, Mollan SP, Harrison D, Taylor D, Lecuona K. Mitomycin $\mathrm{C}$ in the treatment of a Schneiderian (inverted) papilloma of the lacrimal sac. Int Ophthalmol 2010 Jun;30(3): 303-305.

17. Rutenberg M, Kirwan J, Morris CG, Werning JW, Mendenhall WM. Radiation therapy for sinonasal inverted papilloma. Pract Radiation Oncol 2012 Sep [Epub ahead of print].

18. Hanna EY, Cardenas AD, DeMonte F, Roberts D, Kupferman M, Weber R, Rosenthal D, Kies M. Induction chemotherapy for advanced squamous cell carcinoma of the paranasal sinuses. Arch Otolaryngol Head Neck Surg 2011 Jan;137(1):78-81.

19. Okano S, Tahara M, Zenda S, Fuse N, Yoshino T, Doi T, Kawashima M, Ogino T, Hayashi R, Ohtsu A. Induction chemotherapy with docetaxel, cisplatin and S-1 followed by proton beam therapy concurrent with cisplatin in patients with T4b nasal and sinonasal malignancies. Jpn J Clin Oncol 2012;42(8):691-696.

\section{ABOUT THE AUTHORS}

\section{Bandar M Al-Qahtani (Corresponding Author)}

Consultant, Department of Otolaryngology, Head and Neck Surgery King Saud Medical City, Riyadh, Saudi Arabia, Phone: +966-14355555 Ext.3515, e-mail: khamsi20@yahoo.com

\section{Mariam S Al-Amro}

Resident, Department of Otolaryngology, Head and Neck Surgery King Abdulaziz University Hospital, King Saud University, Riyadh Saudi Arabia 